\title{
US-Cuba Health Cooperation: Time to Leverage Easier Access to Cuban Health Innovations
}

\author{
Pierre M. LaRamée MA PhD
}

Over a year ago, Washington and Havana embarked on rapprochement leading to eventual normalization of relations. Much attention has focused on spurring economic activity and expanding opportunities for American travel to Cuba. But many other onerous restrictions are still in place as a result of the US embargo and related policies. It turns out some of them threaten the lives of Americans, by placing obstacles in the way of Cuban biotech and other medical innovations already approved and in use in dozens of other countries. But not in the USA. So we are missing out on the possible health benefits of expanded cooperation with Cuba.

What's at stake is Americans' access to Cuban innovations such as a treatment for diabetic foot ulcers (Heberprot-P) that has shown to reduce risk of amputation by at least $70 \%$. If you consider that there are 73,000 people amputated every year in the United States due to these ulcers, and that half will die within 5 years of losing their limbs, then it's easy to see why the FDA should even fast track clinical trials for this medication.

But that's not happening, because unlike medications from other countries, those developed in Cuba must also obtain two licenses from the US Department of the Treasury. That's right, Treasury, even before being considered by the FDA. One license is needed for trials, and only later, a second license may be considered for sales. But there is no guarantee, even if a drug is FDA-approved, that it will obtain that all-important license for sales, and hence use by physicians. This puts an automatic chill on moving forward, since a company willing to invest in the multimillion-dollar trials still has no assurances that FDA approval will translate into a return on its investment, much less use by critically ill patients. These patients, it should be noted, are disproportionately poor, Native American, African American or Hispanic, they and their families bearing the brunt of this policy....not to mention the expense of treatment, in the billions.

As the debate on Cuba goes on among policymakers and Congress members, people are literally dying. This is wrong, especially in the new climate that has opened the door to win-win US-Cuba cooperation in health.

Luckily, President Obama has the authority to open that door further by using his executive authority. Here are some of the seven key steps the Obama Administration can take to foster US-Cuban cooperation in health, outlined recently in a White Paper published by Medical Education Cooperation with Cuba:[1]

First, treat applications for testing and importing Cuban drugs just as we do those for any pharmaceutical product from a foreign country. Remove the extra barriers of individual Treasury licenses now required, by authorizing a general license to allow Cuban biotech and other innovations - such as therapeutic cancer vaccines and the diabetic foot medication-to follow the same regulatory path through the FDA as drugs developed elsewhere.

Second, issue a general license to allow US pharmaceutical and medical equipment companies to carry out trials in Cuba on their own products, in conjunction with Cuban regulatory authorities and medical institutions, thereby speeding up the process. Cuba's public clinical trials registry is WHO accredited and its research centers are experienced in conducting multicenter trials. These are the FDArequired tests that most often involve thousands of participants. In essence, because Cuba has a unified comprehensive national health system based on primary care in communities, doctors can more easily identify potential participants. The high literacy rate and strict controls on informed-consent enrollment in such trials make Cuba a reliable partner for joint work permitting earlier evaluations of medications to help patients in the USA, Cuba and the world. In another use of his executive powers, the President can even approve an umbrella authorization for collaborative research and joint ventures between US and Cuban medical centers and companies.

While drug development and testing are important, the focus should also be on people who need access to life-saving medications today. Most Americans, like people everywhere, would rather be treated at home. But right now, a diabetic patient seeking Heberprot-P to prevent amputation has no real option but to go to Cuba. However, US law prohibits Americans from receiving medical care there except in case of emergency while traveling. The Obama Administration can issue a general license allowing Americans to go to Cuba for medical treatment, and in fact, for family members to accompany them.

On another front, exchanges between American and Cuban medical, research, public health and disaster mitigation experts simply need to be made easier. Recent developments in bilateral government negotiations are heartening and point to movement in this direction. The Centers for Disease Control and Prevention, Department of Health and Human Services, and National Institutes of Health all have professionals who need to be able to freely talk and cooperate with their counterparts in Cuba. Here's just one reason: the mosquitos that carry the Zika and dengue viruses are now found in 30 states and Puerto Rico, as far north as San Francisco and Boston. Meanwhile, Cuba's Tropical Medicine Institute is the PAHO/WHO Collaborating Center for the study of these viruses and their vectors. Put simply, we need more access to these scientists' accumulated expertise.

And that also goes for knowledge sharing to protect our populations and prevent the spread of other new or reemerging infectious threats, such as SARS and Ebola. We have vital experience and technology to contribute, and we should start working together by design, not default. For the health of Americans, Cubans and people worldwide, cooperation stopped being a vague notion when the USCuba door inched open. It's now an imperative, and there is no time to waste.Thousands of people-maybe millions-would benefit as a result. -1 -

1. A Safer, Healthier Future Through US-Cuba Cooperation, MEDICC White Paper, February 18, 2016 [Internet]. Oakland: Medical Education Cooperation with Cuba; 2016 Feb 18 [cited 2016 Mar 20]. 11 p. Available from: http:// medicc.org/ns/documents/MEDICCWhitePaper2016.pdf

Submitted: March 7, 2016

Approved for publication: April 16, 2016

Disclosures: The author is Executive Director of Medical Education

Cooperation with Cuba, publisher of MEDICC Review.

Correspondence: pmlaramee@mediccglobal.org 